\title{
Endoscopic tattooing of early colon carcinoma enhances detection of lymph nodes most prone to harbor tumor burden
}

\author{
Iban Aldecoa ${ }^{1}$ - Carla Montironi $^{1} \cdot$ Nuria Planell $^{2} \cdot$ Maria Pellise $^{3}$. \\ Gloria Fernandez-Esparrach ${ }^{3} \cdot$ Angels Gines $^{3} \cdot$ Salvadora Delgado $^{4}$. \\ Dulce Momblan $^{4} \cdot$ Leticia Moreira $^{3} \cdot$ Maria Lopez-Ceron $^{3}$ - Natalia Rakislova ${ }^{1}$. \\ Graciela Martinez-Palli ${ }^{5} \cdot$ Jaume Balust $^{5} \cdot$ Josep Antoni Bombi $^{1} \cdot$ Antonio de Lacy $^{4}$. \\ Antoni Castells $^{3} \cdot$ Francesc Balaguer $^{3} \cdot$ Miriam Cuatrecasas $^{1}$
}

Received: 14 February 2016/ Accepted: 6 June 2016/Published online: 20 June 2016

(C) The Author(s) 2016. This article is published with open access at Springerlink.com

\begin{abstract}
Background Colorectal cancer (CRC) screening programs result in the detection of early-stage asymptomatic carcinomas suitable to be surgically cured. Lymph nodes (LN) from early CRC are usually small and may be difficult to collect. Still, at least $12 \mathrm{LNs}$ should be analyzed from colectomies, to ensure a reliable pNO stage. Presurgical endoscopic tattooing improves LN procurement. In addition, molecular detection of occult $\mathrm{LN}$ tumor burden in histologically pNO CRC patients is associated with a decreased survival rate. We aimed to study the impact of presurgical endoscopic tattooing on the molecular detection of LN tumor burden in early colon neoplasms.
\end{abstract}

This work was partially presented at the 26th European Congress of Pathology, London, August 30-September 3, 2014, and as an oral presentation at the DDW 2015, Washington, DC, May 16-19, 2015.

Electronic supplementary material The online version of this article (doi:10.1007/s00464-016-5026-3) contains supplementary material, which is available to authorized users.

\section{Miriam Cuatrecasas}

mcuatrec@clinic.ub.es

1 Pathology Department-Centre de Diagnostic Biomedic (CDB), Hospital Clínic, University of Barcelona (CIBERehd) and Banc de Tumors-Biobanc Clinic-IDIBAPS-XBTC, Escala 3, Planta 5, Villarroel 170, 08036 Barcelona, Spain

2 Bioinformatics Unit, CIBERehd, Barcelona, Spain

3 Gastroenterology Department, Hospital Clinic, IDIBAPS, Centro de Investigación Biomédica en Red de Enfermedades Hepáticas y Digestivas (CIBERehd), University of Barcelona, Barcelona, Catalonia, Spain

4 Surgery Department, Hospital Clinic, Barcelona, Spain

5 Anestesiology Department, ICMDiM, Hospital ClinicIDIPAPS, Barcelona, Spain
Methods A prospective cohort study from a CRC screening-based population was performed at a tertiary academic hospital. LNs from colectomies with and without preoperative endoscopic tattooing were assessed by two methods, hematoxylin and eosin (HE), and RT-LAMP, to detect tumor cytokeratin 19 (CK19) mRNA. We compared the amount of tumor burden and $\mathrm{LN}$ yields from tattooed and non-tattooed specimens.

Results HE and RT-LAMP analyses of 936 LNs were performed from 71 colectomies containing early carcinomas and endoscopically unresectable adenomas (8 pT0, 17 pTis, 27 pT1, 19 pT2); 47 out of 71 (66.2\%) were tattooed. Molecular positivity correlated with the presence of tattoo in LN $[p<0.001$; OR 3.1 (95\% CI 1.7-5.5)]. A significantly higher number of LNs were obtained in tattooed specimens (median $17 \mathrm{LN}$ vs. $14.5 \mathrm{LN} ; p=0.019$ ).

Conclusions Endoscopic tattooing enables the analysis of those LNs most prone to harbor tumor cells and improves the number of LN harvested.

Keywords Colorectal cancer - Lymph nodes - Endoscopic tattooing $\cdot$ India ink $\cdot$ OSNA

Endoscopic tattooing was originally introduced as a reliable and accurate method to localize colonic lesions on follow-up colonoscopies, i.e., incompletely resected polyps or scars from prior polypectomies [1]. Its use has been extended with the introduction of laparoscopic and robotic surgery to locate lesions and determine the extent of colonic resection [1-4]. In addition, colorectal cancer (CRC) population screening programs have increased the detection of early-stage asymptomatic CRC and malignant polyps [5]. This has led to new challenging diagnostic and management issues, including the need to adequately 
define the underlying malignant potential of a certain polyp [6], the decision of endoscopic control or surgical treatment, and the indication for postoperative adjuvant chemotherapy.

Surgically removed early colorectal tumors face the challenge of assessing the lymph node (LN) metastatic potential of a single case, based on the information included in the histopathology report [7]. Considering that LN staging is an accurate prognostic factor, there is a broad consensus on the need to achieve the highest number of LNs [7-9]. In order to increase histological diagnostic sensitivity, gross LN enhancement with nodal revealing solutions [10] and molecular LN staging assessment have been proposed [11-18]. Nevertheless, despite the evidences of impaired survival rates associated with the molecular detection of tumor cells in regional LN of stage I-II CRC patients $[12,14,19]$, LN molecular analysis is not performed on a daily basis, mainly due to its high costs and time-consuming nature.

Moreover, the impact of presurgical submucosal tattooing on the LN yield obtained is controversial [9, 20-22]. Methodological differences in the type and number of $\mathrm{LN}$ studied, as well as the different aims of the studies, may account for the discrepancies, i.e., some authors have used India ink to identify sentinel lymph nodes (SLN), advocating that it may help to identify metastatic LN, while others have used it for $\mathrm{LN}$ mapping and increasing the number of LN [20, 23-25].

The aim of this study was to assess the impact of endoscopic tattooing on the molecular detection of $\mathrm{LN}$ tumor burden in early colon neoplasia. We used the molecular assay one-step nucleic acid amplification (OSNA, Sysmex Corporation, Kobe, Japan), which is based on the quantitative detection of cytokeratin 19 (CK19) mRNA. This technique is widely used in the evaluation of breast cancer SLN [26] and is being introduced to assess regional $\mathrm{LN}$ in colon [27, 28], lung [29], endometrial [30], and thyroid cancer [31]. In addition, we also aimed to assess the enhancement of $\mathrm{LN}$ procurement in tattooed colectomies.

\section{Materials and methods}

\section{Patients}

From May 2012 to December 2013, we included all patients submitted to surgery for colon carcinomas or endoscopically unresectable adenomas diagnosed at our institution. The study was performed in the context of a population-based CRC screening program using fecal immunochemical test (FIT) (OC-Sensor ${ }^{\circledR}$, Eiken, Japan; cutoff, $\geq 20 \mu \mathrm{g}$ of hemoglobin/g of feces). FIT was offered every 2 years to asymptomatic individuals between 50 and 69 years old.

This study is focused on the molecular identification of LN metastasis in early colon neoplasms (pT0-2) and the influence of tattooing in this setting. We included individuals over 18 years old with endoscopically unresectable adenomas, malignant polyps with confirmed pT1 carcinoma containing adverse prognostic factors associated with $\mathrm{LN}$ metastasis (i.e., the presence of at least one of the following features: poor differentiation, lymphovascular invasion, high-grade tumor budding, tumor margin $\leq 1 \mathrm{~mm}$, and submucosal invasion $\geq 2 \mathrm{~mm}$ ), and pT1-2 stage colon carcinomas. pT3-4 carcinomas were excluded since they are seldom tattooed at our institution as they are regarded as large infiltrating masses easy to be surgically localized. Other exclusion criteria were tumor infiltration of the mesocolon fat on gross examination, rectal tumors, synchronous colorectal carcinomas, appendicular carcinomas, the presence of colonic stent, inflammatory bowel disease or other malignancies, and reception of surgical specimen immersed in formalin.

\section{Ethical considerations}

The study was approved by the Ethics Committee of Hospital Clinic of Barcelona, Spain. All patients signed and kept a copy of the informed consent document for participation in the study. Another copy was kept with the patient's clinical files.

\section{Study procedures}

\section{Colonoscopy and tattooing}

Colonoscopies were performed on patients with a positive FIT result. Our institution has a high-quality endoscopy unit dedicated to screening and follow-up colonoscopy, with highly skilled, experienced endoscopists (performing more than 200 endoscopies per year), and quality assurance controls according to the European guidelines on quality in screening colonoscopy [32]. The standard practice of colonoscopy tattooing to provide accurate localization of lesions for later identification is performed at the endoscopist criteria, following the clinical protocols of the Gastroenterology Department at Hospital Clínic, Barcelona, Spain, performed in compliance with the European guidelines [32]. Thus, colonoscopy tattooing is performed after removal of 2-cm polyps or larger, and on all suspicious lesions at colonoscopy situated outside of the cecum or rectum: namely non-resectable polyps, lesions suspected of submucosal invasive carcinoma, or endoscopically partially resected advanced adenomas $(>10 \mathrm{~mm}$, villous, or after a pathology diagnosis of high-grade dysplasia). 
For tattooing, $10 \%$ of diluted and sterilized commercial India ink was used (Pelikan drawing ink color black (A17), Pelikan Vertriebsgesellschaft mbH \& Co. KG, Hannover, Germany), which was crafted at the Pharmacy Department of Hospital Clinic by mixing $6 \mathrm{ml}$ of ink and $54 \mathrm{ml}$ of bi-distilled water, divided in 2-mL glass vials, closed, and sterilized by autoclaving at $120{ }^{\circ} \mathrm{C}$ for $20 \mathrm{~min}$. India ink tattooing was performed by injection of $1 \mathrm{~mL}$ of ink in the submucosa adjacent to the lesion after previous saline submucosal injection, to verify its correct location and to avoid ink injection into the peritoneum (Fig. 1a). For lesions located at the sigmoid or ascending colon, tattoos were placed 1 to $2 \mathrm{~cm}$ distally to the lesion and on two opposite sides of the colonic lumen. For lesions located at the transverse colon, tattoos were placed both distally and proximally to the lesion and on both sides of the lumen (i.e., at 3 and 9 o'clock).
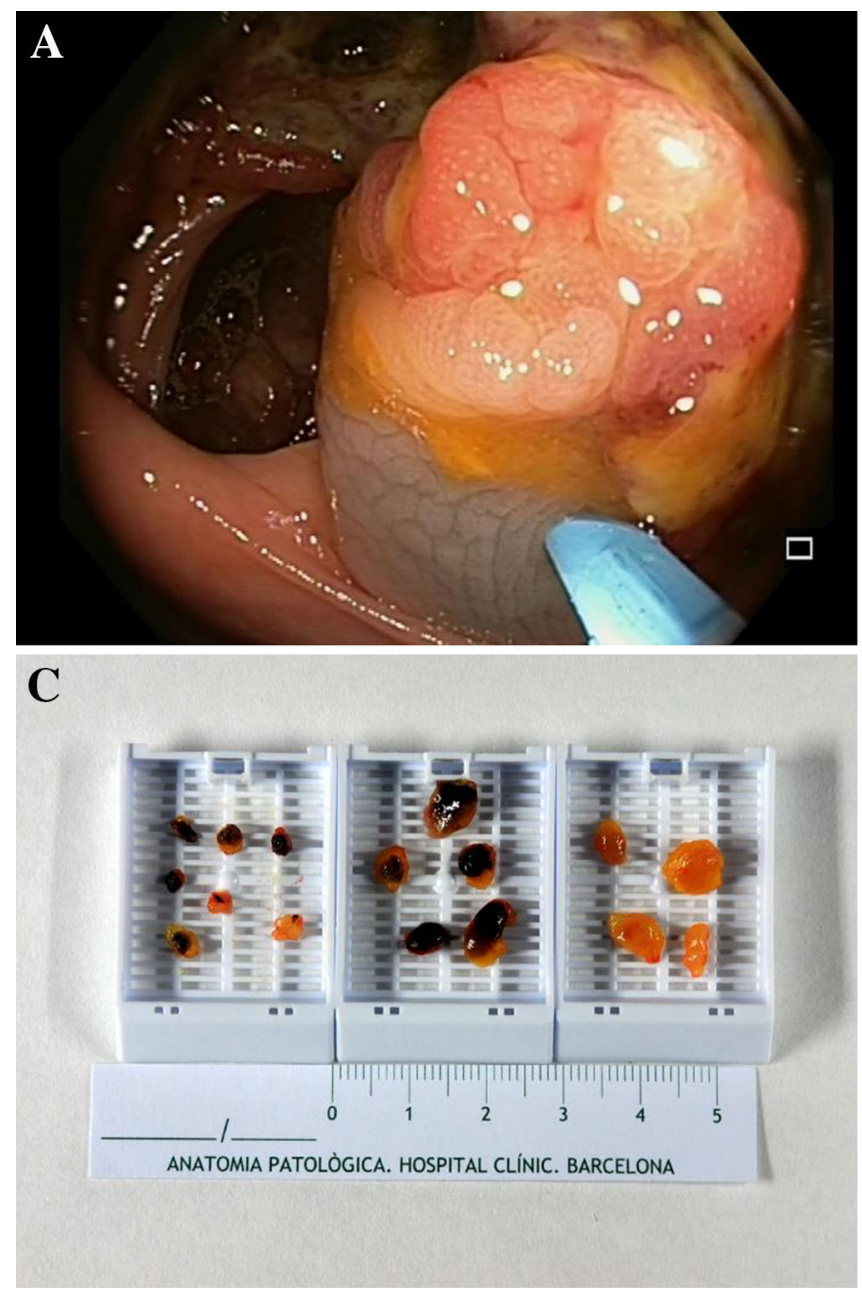

Fig. 1 A Endoscopic tattooing of a colon carcinoma. Notice submucosal ink injection adjacent to the lesion; B gross surgical specimen of a right-side hemicolectomy with tattooed area near an advanced adenoma. Ruler in centimeters; $\mathbf{C}$ lymph nodes harvested from one surgical specimen. The darker tonalities of tattooed lymph

\section{Surgery}

Laparoscopy-assisted colectomy under general anesthesia was performed in all patients by a single gastrointestinal surgical team with wide experience in laparoscopic procedures [4]. Throughout the operation, a pneumoperitoneum with intra-abdominal pressure between 10 and $14 \mathrm{mmHg}$ was maintained. In all patients, colon resection was carried out following oncological criteria, consisting in proximal vessel ligation, en bloc lymphadenectomy, and broad macroscopic resection margins. Routine measures used to prevent port-site metastasis included initial vascular ligation, the use of a wound edge protector, reduction in intra-abdominal pressure before tumor extraction, and exhaustive cleansing with $5 \%$ iodopovidone solution.

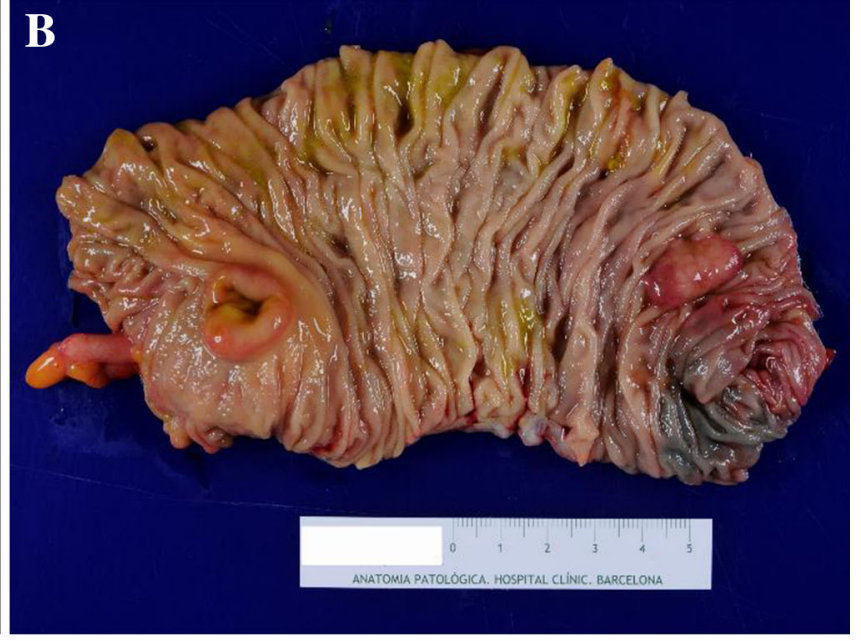

D

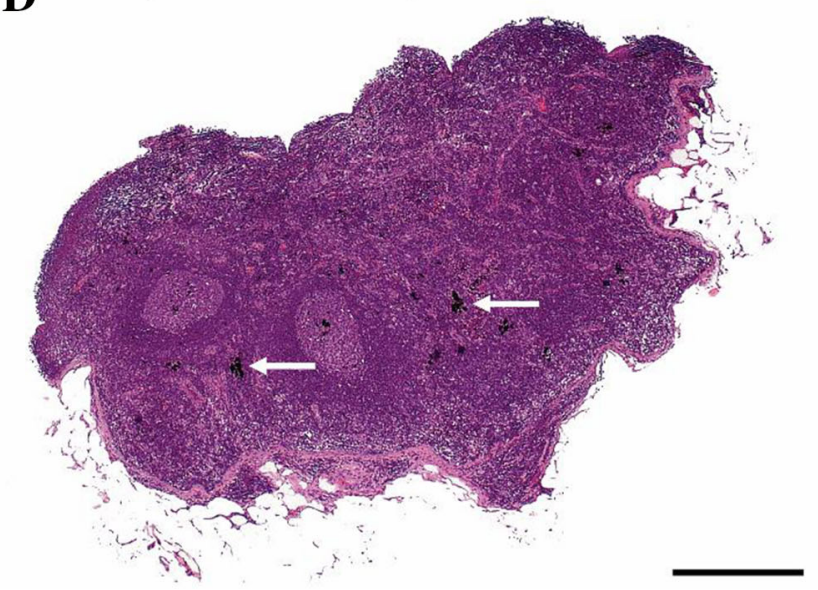

nodes eased their procurement. Notice the left cassette with some small tattooed lymph nodes. A few lymph nodes placed on the right cassette had no ink. Ruler in centimeters; D histological HE section of a LN with presence of carbon particles inside (arrows) from previous tattooing (scale bar $500 \mu \mathrm{m})$ 


\section{Surgical specimens}

The study included colectomies containing adenocarcinomas, partially resected advanced adenomas, non-resectable polyps, adenomas with suspicion of submucosal invasive carcinoma, and endoscopically resected malignant polyps that contained adverse prognostic factors listed above, which required complete colectomy (Fig. 1B). Pathological data from both endoscopically and surgically resected neoplasms were collected and recorded (Table 1). Patient's staging resulted from the pathological evaluation of both endoscopic and surgical specimens. Gross processing and pathology reports were performed according to the protocols of the pathology department, adopted from the latest version of the colorectal protocol of the AJCC [33]. All cases were diagnosed and reviewed by two senior gastrointestinal pathologists (JAB, MC).

\section{Lymph node harvest}

Lymph nodes from all surgical specimens were identically procured and assessed (Fig. 1C). LNs were also dissected and analyzed from colectomies with no residual tumor performed after an endoscopic polypectomy containing a pT1 carcinoma with adverse prognostic factors. Fresh LN procurement from the mesocolon fat was performed at the pathology department within $50 \mathrm{~min}$ after surgical resection by four pathologists, IA, CM, NR, and MC. Fresh LNs were sectioned and submitted for both conventional histology with HE and the OSNA molecular assay, for the detection and amplification of tumor CK19 mRNA [28]. A second-look LN search was performed after $18-30 \mathrm{~h}$ of formalin fixation. LNs revealing solutions (i.e., alcohol) were not used. All formalin-fixed paraffin-embedded (FFPE) LNs were submitted only for HE analysis. The presence of India ink in the LN was recorded after evaluation of the HE slides from all LNs using a conventional Olympus BX41 microscope (Olympus, Tokyo, Japan) (Fig. 1D).

\section{OSNA lymph node molecular analysis for CK19 mRNA quantification}

The OSNA method was performed following the manufacturer's instructions, using a modified protocol from Tsujimoto et al. [28, 34, 35]. In this assay, the amount of CK19 mRNA/ $\mu \mathrm{L}$ copies correlates with the size of the metastasis [34]. The results were based on the number of CK19 mRNA copies/ $\mu \mathrm{L}$ obtained for each $\mathrm{LN}$, with a cutoff of $100 \mathrm{CK} 19$ mRNA copies/ $\mu \mathrm{L}$. Values from 100 to $250 \mathrm{CK} 19 \mathrm{mRNA}$ copies $/ \mu \mathrm{L}$ corresponded to isolated tumor cells (ITC). The total tumor load (TTL) of a given specimen resulted from the sum of all CK19 mRNA copies/ $\mu \mathrm{L}$ from each positive LN. Evaluation of the molecular results was performed blindly with respect to both clinical and pathological assessments.

\section{India ink and OSNA assay interference test}

In order to determine whether the carbon particles from India ink interfered with the RT-LAMP reaction, we tested the RT-LAMP CK19 mRNA reaction with and without India ink at 1:100 dilution, which represents a surplus of carbon particles compared to the real traces of carbon particles present in the LN of a tattooed surgical specimen. From a $2000 \mu \mathrm{L}$ mix containing $20 \mu \mathrm{L}$ of the positive control containing human CK19 mRNA sample and $1980 \mu \mathrm{L}$ of lysis buffer Lynorhag (Sysmex Corp. Kobe, Japan), we transferred $200 \mu \mathrm{L}$ of the mix into 10 OSNA vials and performed the analysis using the Lynoamp BC gene amplification reagent (Sysmex Corp. Kobe, Japan). The same process was done with $20 \mu \mathrm{L}$ of India ink, $20 \mu \mathrm{L}$ of positive control CK19 mRNA sample, and $1960 \mu \mathrm{L}$ of Lynorhag (Sysmex). The amplification product was detected by measuring the rise time required to exceed a predetermined threshold turbidity caused by the by-product magnesium pyrophosphate. The values obtained among samples with high concentration of India ink and without India ink were not significant, showing the absence of India ink interference in the RT-LAMP reaction (Supplementary figure).

\section{Outcomes}

The main outcome was to compare the presence of CK19 mRNA tumor burden in LN among tattooed and non-tattooed specimens.

The secondary outcome was to determine the differences in the yield of LN procured in tattooed and nontattooed specimens.

\section{Statistical analysis}

Continuous variables were described as median and interquartile ranges (IQR), and categorical variables as absolute frequencies and percentages. Spearman's rank correlation coefficient was applied to assess correlation between continuous variables. The association of categorical variables was assessed by Fisher's exact test. The Mann-Whitney-Wilcoxon test was performed to analyze the statistical significance of differences in continuous parameters. Cohen's kappa was used to assess the degree of agreement. A mixed-effects logistic model with a random patient effect was used to assess the prediction of OSNA outcome in tattooed cases. A $p$ value of $<0.05$ was considered statistically significant. All analyses were performed using R statistical environment (V.3.0.2) [36]. 
Table 1 Patient demographics and specimen characteristics

\begin{tabular}{|c|c|c|c|c|}
\hline Variables & Total & Tattooed specimens & Non-tattooed specimens & $p$ value \\
\hline Cases & 71 & 47 & 24 & \\
\hline Gender & & & & 0.61 \\
\hline Male & $43(60.6)$ & $27(57.4)$ & $16(66.7)$ & \\
\hline Female & $28(39.4)$ & $20(42.6)$ & $8(33.3)$ & \\
\hline Age (years) & $64(59-70)$ & $63(59-68)$ & $66(62-74)$ & 0.15 \\
\hline \multicolumn{5}{|c|}{ Surgical specimen characteristics } \\
\hline Specimen size $(\mathrm{cm})$ & $14(11-18)$ & $14(12-17.3)$ & $13.3(10.9-19.3)$ & 0.93 \\
\hline Adenocarcinoma size $(\mathrm{cm})$ & $1.5(0.9-3)$ & $1.5(0.9-2.5)$ & $1.8(0.8-3.4)$ & 0.62 \\
\hline Tumor location & & & & 0.12 \\
\hline Cecum & $12(16.9)$ & $4(8.5)$ & $8(33.3)$ & \\
\hline Ascending colon & $16(22.5)$ & $9(19.1)$ & $7(29.2)$ & \\
\hline Hepatic flexure & $3(4.2)$ & $3(6.4)$ & $0(0.0)$ & \\
\hline Transverse colon & $6(8.5)$ & $6(12.8)$ & $0(0.0)$ & \\
\hline Splenic flexure & $5(7.0)$ & $3(6.4)$ & $2(8.3)$ & \\
\hline Descending colon & $3(4.2)$ & $3(6.4)$ & $0(0.0)$ & \\
\hline Sigmoid colon & $26(36.6)$ & $19(40.4)$ & $7(29.2)$ & \\
\hline Surgical specimen type ${ }^{\mathrm{a}}$ & & & & 0.17 \\
\hline Completely resected & $18(25.3)$ & $15(31.9)$ & $3(12.5)$ & \\
\hline Partially resected & $6(8.5)$ & $3(6.4)$ & $3(12.5)$ & \\
\hline Non-resected & $47(66.2)$ & $29(61.7)$ & $18(75.0)$ & \\
\hline Lymphovascular invasion $^{\mathrm{b}}$ & & & & 0.09 \\
\hline No & $65(91.5)$ & $41(87.2)$ & $24(100)$ & \\
\hline Yes & $6(8.5)$ & $6(12.8)$ & $0(0.0)$ & \\
\hline Grade & & & & 0.15 \\
\hline High grade & $9(12.7)$ & $8(17.0)$ & $1(4.2)$ & \\
\hline Low grade & $62(87.3)$ & $39(83.0)$ & $23(95.8)$ & \\
\hline MS instability & $5(7.0)$ & $2(4.3)$ & $3(12.5)$ & 0.33 \\
\hline Tumor budding $(n=43)^{\mathrm{c}}$ & & & & 1.00 \\
\hline High grade & $30(69.8)$ & $21(70.0)$ & $9(69.2)$ & \\
\hline Low grade & $13(30.2)$ & $9(30.0)$ & $4(30.8)$ & \\
\hline pTMN & & & & 0.53 \\
\hline pT0 & $8(11.3)$ & $4(8.5)$ & $4(16.7)$ & \\
\hline pTis & $17(23.9)$ & $10(21.3)$ & $7(29.2)$ & \\
\hline pT1 & $27(38.0)$ & $20(42.6)$ & $7(29.2)$ & \\
\hline pT2 & $19(26.8)$ & 13 (27.7) & $6(25.0)$ & \\
\hline
\end{tabular}

Categorical variables are shown as absolute frequencies and percentages. Numerical variables are described as median and interquartile range (IQR)

${ }^{a}$ With respect to the endoscopic resection

b In one case, lymphatic invasion could not be assessed

c Tumor budding was assessed in 43 infiltrating carcinomas

\section{Results}

\section{Sample characteristics}

The flowchart of the study is detailed in Fig. 2. A total of 2980 colonoscopies were performed on patients with a positive FIT result. We excluded 1820 patients who had a normal colonoscopy or non-advanced adenomas which were endoscopically treated. We found 140 CRC and 1020 advanced adenomas. Most of the latter were endoscopically treated. A total of 103 surgically treated cases were included for LN analysis with OSNA and HE. Of them, 32 pT3-4 carcinomas were excluded. Finally, 71 patients met the study selection criteria. These individuals comprised of (a) 18 patients with endoscopically resected malignant polyps with adverse prognostic factors submitted to 


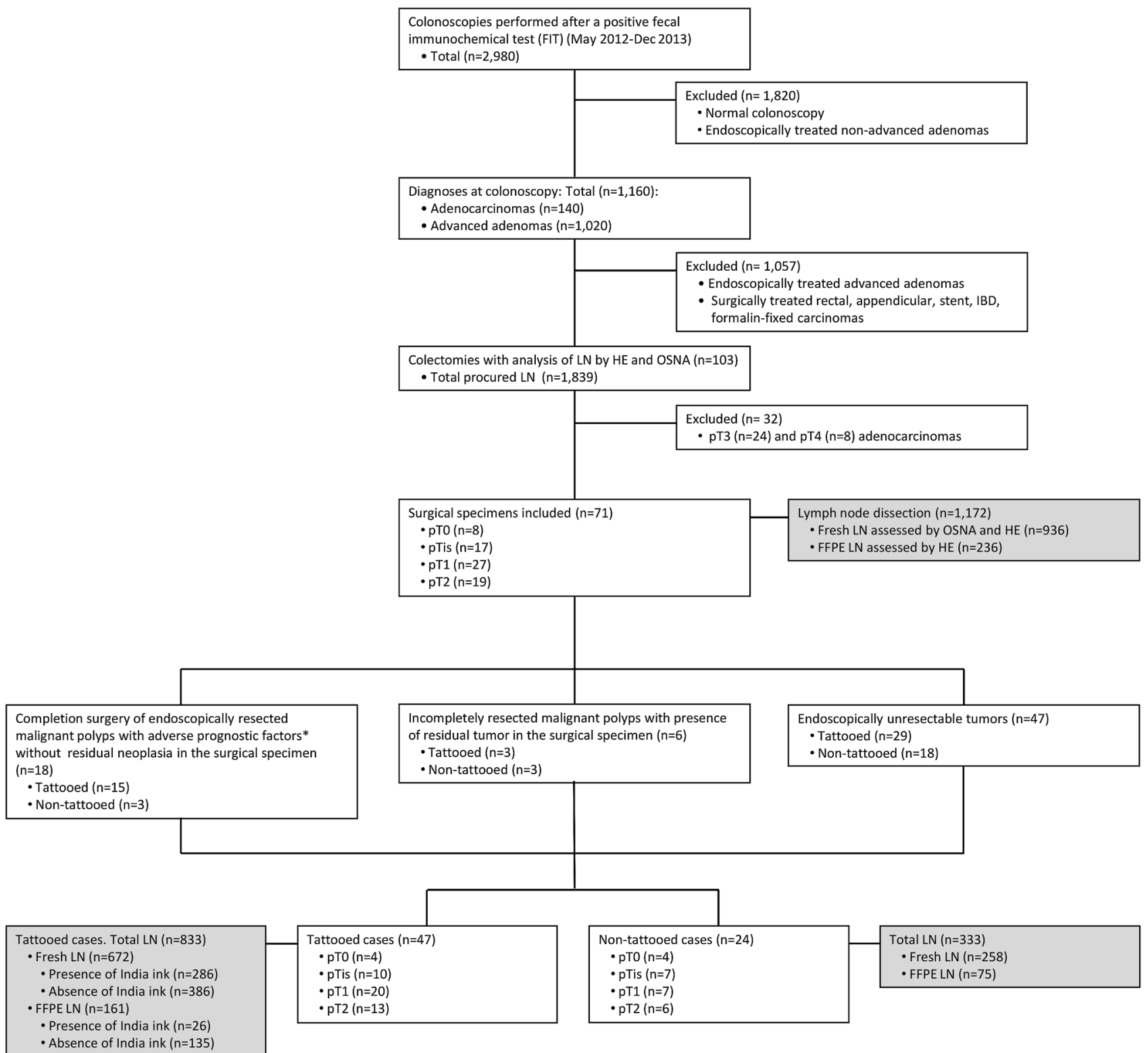

Fig. 2 Study flow diagram. Selection and classification of patients according to endoscopic tattooing and pathological findings. *The presence of at least one of the following features: poor differentiation,

surgery. No residual tumor was found in the colectomy specimen; (b) 6 patients with partially resected malignant polyps at colonoscopy, with the presence of residual tumor in the surgical specimen; and c) 47 patients with endoscopically unresectable tumors.

Colectomy specimens were $14 \mathrm{~cm}$ (IQR $11-18 \mathrm{~cm})$ in average size. Forty-seven $(66.2 \%)$ cases were tattooed and $24(33.8 \%)$ non-tattooed. The median period of time between endoscopic tattooing and surgery was 63 days (IQR 38-92 days). No differences were observed between both groups regarding demographic and pathologic specimen characteristics (Table 1). The median adenocarcinoma lymphovascular invasion, high-grade tumor budding, tumor margin $\leq 1 \mathrm{~mm}$, submucosal invasion $>2 \mathrm{~mm}$

size was $1.5 \mathrm{~cm}$ (IQR $0.9-3.0 \mathrm{~cm}$ ). Two cases had LN metastases on HE analysis. Regarding classical high-risk factors, 9 carcinomas contained high-grade areas and 6 presented angiovascular invasion. Perineural invasion was not observed in any case.

\section{Lymph node assessment}

The number of LN assessed in this study is detailed at the bottom of the flowchart (Fig. 2) and in Table 2. From the 71 surgical specimens included, 1172 LNs were procured; $936(79.9 \%)$ were freshly dissected and analyzed for both 
OSNA and HE. After formalin fixation, 236 (20.1\%) LNs were obtained and analyzed with HE. A median of 15 lymph nodes was obtained per patient, 12 of them freshly harvested. The number of total LN procured per case was significantly higher in tattooed cases (median, 17 LNs in tattooed specimens vs. 14.5 LNs in non-tattooed specimens; $p=0.019$ ) (Table 2).

Fresh LN procurement was performed within a median of $30 \mathrm{~min}$ (IQR 20.0-38.5 min). Although no differences were found in time expended on LN harvesting among tattooed and non-tattooed cases, a significant reduction in the harvesting time was observed in the former, when LN search time was corrected by the number of LN collected $(p=0.014$, Table 2).

\section{Analysis of the presence of India ink and tumor CK19 mRNA in LN among tattooed cases}

We assessed with the optical microscope the presence of traces of India ink in the form of carbon particles among the 833 LNs obtained from the 47 tattooed cases; 672 LNs were freshly collected. India ink was present in a total of 312 LNs (286; $42.6 \%$ fresh LNs, and 26; $16 \%$ FFPE), See flowchart in Fig. 2. Carbon particles were present in a median of 7 LNs (IQR 4-8) per case.

Twenty-nine tattooed patients were positive for CK19 mRNA $(61.7 \%)$. We analyzed the association between the presence of India ink in $\mathrm{LN}$ and the detection of tumor CK19 mRNA (Table 2). Of the 672 freshly harvested LNs, $72(10.7 \%)$ contained tumor CK19 mRNA (44 LNs with
India ink and 28 without). Importantly, $15.3 \%$ (44/286) of LNs with carbon particles contained tumor CK19 mRNA, while less than $7.3 \%(28 / 386)$ of LNs without India ink were positive for CK19 mRNA (Table 3). The logistic model with a random patient effect gave a significant effect of ink $(p<0.001)$ in the CK19 mRNA detection with an odds ratio of 3.1 (95\% CI 1.7-5.5).

\section{Analysis of CK19 mRNA in the whole cohort}

CK19 mRNA assessment revealed the presence of traces of tumor CK19 mRNA in LN of 42 out of 71 cases (59.2\%). The median TTL was 1350 (IQR 640-2938) CK19 mRNA copies $/ \mu \mathrm{L}$. Two tattooed cases with LN metastases on HE had a significantly higher TTL of 560,000 and 41,160 CK19 mRNA copies/ $\mu \mathrm{L}$, respectively. The median TTL of patients with histologically negative LN was 1275 CK19 mRNA copies/ $\mu \mathrm{L}$ (IQR 620-2262). Additional analysis between OSNA results and classical high-risk factors showed an association with tumor size (positive cases showed larger tumors $(p=0.02))$ and higher tumor grade $(p<0.01)$ (data not shown).

\section{Treatment and clinical follow-up}

All patients were surgically treated by a high-volume practice surgical team specialized in laparoscopic CRC surgery. The two patients with positive LN on HE received adjuvant chemotherapy. Median follow-up was 984 days (IQR 801.5-1118.5 days). Two patients developed distant

Table 2 Lymph node characteristics per case

\begin{tabular}{lccc}
\hline Variables & Total $(n=71)$ & $\begin{array}{l}\text { Tattooed specimens } \\
(n=47)\end{array}$ & $\begin{array}{l}\text { Non-tattooed specimens } \\
(n=24)\end{array}$ \\
\hline Total lymph nodes & $15(12-20)$ & $17(13-21)$ & $14.5(10-17)$ \\
Fresh lymph nodes & $12(9-16.5)$ & $13(10-18)$ & $10.5(7.7-13.2)$ \\
FFPE lymph nodes & $2(1-5)$ & $2(1-5)$ & $3(1.7-4.2)$ \\
Lymph node harvest time (min) $)^{\mathrm{a}}$ & $30(20-38.5)$ & $30(20-38.5)$ & $27.5(20-36.2)$ \\
Lymph node harvest time (min) adjusted per & $2.2(1.8-3.0)$ & $2.1(1.8-2.5)$ & $3.2(1.9-3.8)$ \\
$\quad$ LN & & & 0.019 \\
CK19 mRNA detection & $42(59.2)$ & $29(61.7)$ & $13(54.2)$ \\
$\quad$ CK19 mRNA detected & $29(40.8)$ & $18(38.3)$ & $11(45.8)$ \\
CK19 mRNA not-detected & $1350(640-2938)$ & $1420(700-4270)$ & $1270(620-2200)$ \\
TTL & & & 0.91 \\
\hline
\end{tabular}

Categorical variables are shown as absolute frequencies and percentages. Numerical variables are described as median and interquartile range (IQR)

FFPE formalin-fixed paraffin-embedded

a Time spent on fresh lymph node harvesting per case

b Total tumor load (TTL) was calculated as the sum of CK19 mRNA copies/ $\mu \mathrm{L}$ from all positive lymph nodes in one given case. The median and IQR shown was obtained from the cohort of positive CK19 mRNA cases $(n=42)$ 
Table 3 CK19 mRNA detection in tattooed and non-tattooed lymph nodes

\begin{tabular}{llll}
\hline & Total LN no. $(\%)$ & Tattooed LN no. $(\%)$ & Non-tattooed LN no. $(\%)$ \\
\hline CK19 mRNA detected & $72(100)$ & $44(61.1)$ & $28(38.9)$ \\
CK19 mRNA not-detected & $600(100)$ & $242(40.3)$ & $358(59.7)$ \\
Total LN & 672 & 286 & 386 \\
\hline
\end{tabular}

$L N$ lymph node

metastases at 4 and 21 months after surgery, respectively. Both patients presented pT2N0 right-sided tumors with no high-grade features and comparable tumor sizes (30 and $25 \mathrm{~mm}$ ). The first patient was not tattooed, with 14 out of 18 LNs analyzed by OSNA, and a high TTL of 47,760 CK19 mRNA copies/ $\mu \mathrm{L}$. The second patient was a tattooed case, negative for CK19 mRNA detection, but had only 10 LNs analyzed by OSNA out of 20 procured LNs.

\section{Discussion}

Colonoscopic submucosal tattooing was originally developed to aid in the localization of colon tumors by the endoscopist and surgeon. Although it has been a useful clinically oriented method [1-4], its impact on and benefit in relation to $\mathrm{LN}$ retrieval and CRC staging is controversial [9, 20-25]. While some studies find that preoperative tattooing improves LN harvest [9, 20, 21, 24], other publications with divergent results have recently appeared [22]. It is widely accepted that the number of pathologically assessed LN is a critical issue, as it has been demonstrated that it correlates with survival, particularly for node-negative colon cancer patients. In fact, the greater the number of LN examined, the greater the chance to detect metastases [7-9]. Current guidelines recommend that at least 12 LNs should be pathologically assessed to ensure an adequate specimen evaluation and a reliable pathologic staging [33, 37].

Although the number of LN obtained depends on patient, surgical and pathological factors, the latter are decisive and may include revealing solutions that ease LN procuring, i.e., ether and alcohol. [7, 9, 38]. It seems that placement of tattoo by injection of carbon-based dyes causes a permanent deposit of carbon particles in $\mathrm{LN}$, resulting in a dark stain of the LN which helps gross detection and dissection, especially of small-sized LN. Of notice, the median time period between endoscopic tattooing and surgical resection in our study was of 63 days, with a correct microscopic analysis of the presence of carbon particles, being in other series from intraoperative injection to 30 days between both events [20-22, 24].
In agreement with previous studies [9, 20, 21, 23-25], we have evaluated the usefulness of presurgical colonoscopic tattooing to obtain higher $\mathrm{LN}$ retrievals. We obtained a median of $17 \mathrm{LNs}$ in tattooed colectomies compared to $14.5 \mathrm{LNs}$ in non-tattooed ones $(p=0.02)$. We obtained at least $12 \mathrm{LNs}$ in $87.3 \%$ of tattooed cases, in compliance with international guidelines [33], which represented an increase of $20.6 \%$ with respect to non-tattooed cases.

Nodal metastases in early CRC are often present in small, difficult to identify, LN of $<5 \mathrm{~mm}$ in greatest diameter [17, 18, 33]. Presurgical colonoscopic tattooing enabled us to easily detect those LNs. The presence of tattooing may also enhance the likelihood of harvesting the first level of nodal drainage, as well as other LNs in the drainage basin that can also shelter metastatic disease [9, 20, 23, 25]. Spatz et al. [23] analyzed 311 LNs from 21 specimens concluding that colonoscopic tattooing is potentially beneficial for appropriate colon cancer staging.

Our results reinforce previous findings, having found a significantly higher amount of tumor CK19 mRNA among tattooed LNs, with an odds ratio of 3.1 ( $p<0.001)$. In our study, we tried to evaluate the practical benefit of a tattooed specimen. As Bartels did, we considered cases to be tattooed only when they had traces of India ink either at gross or at LN microscopic analysis [20]. Differences in methodology and limitations of previous studies may account for controversial results. Feo et al. [22] retrospectively studied 250 colorectal specimens divided into two cohorts, with and without preoperative colonoscopic tattooing. They concluded that preoperative tattooing did not improve the LN yield. Nevertheless, histologic assessment seeking for LN carbon deposits was performed in only 30 out of 107 tattooed cases. They found LN carbon particles in only 2 of the 30 cases [22]. In our prospective cohort, all 47 tattooed cases had gross and histologic traces of carbon particles.

The prognostic significance of LN tumor burden detection using molecular techniques has already been established for breast and CRC [12-16, 26, 39]. Several metaanalyses have found an independent significant association between molecular LN tumor detection and an increased 
risk of disease recurrence and poor survival in CRC patients $[12-15,19,40]$. Nevertheless, tumor burden detected using molecular techniques may not always be clinically relevant. A study using RT-qPCR detection of guanylyl cyclase $\mathrm{C}$ in colon cancer patients found positive LN in $87.5 \%$ of them, although only $20.9 \%$ developed recurrent disease [13]. Other highly sensitive molecular techniques, such as liquid biopsy, have also demonstrated the presence of circulating cell-free tumor DNA in patients with precursor lesions and in situ carcinomas [41, 42].

The aim of our study was not to prove the prognostic significance of LN tumor burden detection using molecular techniques, but to demonstrate the usefulness of tattooing in the detection of those LN most prone to hold tumor burden. For that reason, we included in our analysis those LN holding isolated tumor cells, or small traces of tumor CK19 mRNA, which are known to date to have no clinical significance. In other studies using OSNA, the presence of small amounts of TTL is overlooked. In fact, TTL over 15,000 CK19 mRNA copies/ $\mu \mathrm{L}$ has been settled for breast and thyroid cancer sentinel $\mathrm{LN}$ studies to determine the likelihood of additional nodal metastases [26, 31]. In our study, the TTL obtained was much lower, with a median of 1350 CK19 mRNA copies/ $\mu \mathrm{L}$ per patient. Interestingly, patients with high TTL had either disease recurrence or LN metastases, except for one patient with disease recurrence that had only $50 \%$ of the retrieved LN assessed by OSNA. Forthcoming studies are needed in CRC to determine the amount of clinically significant nodal total tumor load.

Our study has some drawbacks. Firstly, it was performed in a single institution and has a small number of cases analyzed, although it was performed in a screening-based program which allowed us to obtain early-stage carcinomas. Secondly, the distance of the tattoo from the neoplastic lesion was not recorded and, therefore, the correlation between this variable and the CK19 mRNA values could not be ascertained.

Our study highlights colonoscopic tattooing as a highly efficient LN procurement. Tattooing helps the endoscopist and the surgeon to localize the tumor. In addition, it can be used as an extra pathology tool to harvest a higher amount of LN, but more importantly, it makes it possible to find those LNs which might shelter tumor. In a CRC screeningbased population, an expanded use of presurgical endoscopic tattooing could benefit patient's diagnosis and therapeutic management.

Acknowledgments Mireia Aragay, Becky, and Steve Charous were acknowledged for their help with the language editing.

Funding Work supported by the Banc de Tumors-Biobanc Hospital Clinic-IDIBAPS and Xarxa de Bancs de Tumors de Catalunya (XBTC), and by grants from the Fundación Científica de la Asociación Española Contra el Cáncer (GCB13131592CAST), Ministerio de Economía y Competitividad (SAF2014-54453-R), and Agència de Gestió d'Ajuts Universitaris i de Recerca (2014SGR135) was acknowledged. The work was sponsored by Sysmex Corporation, Kobe, Japan. CIBERehd is funded by the Instituto de Salud Carlos III.

Author contributions M.C., M.P., A.C., and I.A. were involved in study conception and design; I.A., C.M., G.F., A.G., S.D., D.M., L.M., and G.M. were responsible for data acquisition; M.C., I.A., and N.P. were involved in statistical analysis and data interpretation; M.C., I.A., and M.P. drafted the manuscript; M.P., F.B., and A.C. critically revised the article for important intellectual content; M.C. and A.C. finally approved the article.

\section{Compliance with ethical standards}

Disclosures None of the authors of this manuscript, Iban Aldecoa M.D.; Carla Montironi M.D.; Nuria Planell B.Sc; Maria Pellise M.D., $\mathrm{PhD}$; Gloria Fernandez-Esparrach M.D., PhD; Angels Gines M.D., PhD; Salvadora Delgado M.D., PhD; Dulce Momblan M.D.; Leticia Moreira M.D., PhD; Maria Lopez-Ceron M.D., PhD; Natalia Rakislova M.D.; Graciela Martínez-Palli M.D., PhD; Jaume Balust M.D.; Josep Antoni Bombi M.D., PhD; Antonio de Lacy M.D., PhD; Antoni Castells M.D., PhD; Francesc Balaguer M.D., PhD; and Miriam Cuatrecasas M.D., PhD, have any conflicts of interest or financial ties to disclose.

Open Access This article is distributed under the terms of the Creative Commons Attribution 4.0 International License (http://crea tivecommons.org/licenses/by/4.0/), which permits unrestricted use, distribution, and reproduction in any medium, provided you give appropriate credit to the original author(s) and the source, provide a link to the Creative Commons license, and indicate if changes were made.

\section{References}

1. Ellis KK, Fennerty MB (1997) Marking and identifying colon lesions. Tattoos, clips, and radiology in imaging the colon. Gastrointest Endosc Clin N Am 7:401-411

2. Yeung JMC, Maxwell-Armstrong C, Acheson AG (2009) Colonic tattooing in laparoscopic surgery-making the mark? Colorectal Dis 11:527-530. doi:10.1111/j.1463-1318.2008. 01706.x

3. Beretvas RI, Ponsky J (2001) Endoscopic marking: an adjunct to laparoscopic gastrointestinal surgery. Surg Endosc 15:1202-1203. doi:10.1007/s004640000304

4. Lacy AM, García-Valdecasas JC, Delgado S, Castells A, Taurá P, Piqué JM, Visa J (2002) Laparoscopy-assisted colectomy versus open colectomy for treatment of non-metastatic colon cancer: a randomised trial. Lancet 359:2224-2229. doi:10.1016/S01406736(02)09290-5

5. Quintero E, Castells A, Bujanda L, Cubiella J, Salas D, Lanas Á, Andreu M, Carballo F, Morillas JD, Hernández C, Jover R, Montalvo I, Arenas J, Laredo E, Hernández V, Iglesias F, Cid E, Zubizarreta R, Sala T, Ponce M, Andrés M, Teruel G, Peris A, Roncales M-P, Polo-Tomás M, Bessa X, Ferrer-Armengou O, Grau J, Serradesanferm A, Ono A, Cruzado J, Pérez-Riquelme F, Alonso-Abreu I, de la Vega-Prieto M, Reyes-Melian JM, Cacho G, Díaz-Tasende J, Herreros-de-Tejada A, Poves C, Santander C, González-Navarro A (2012) Colonoscopy versus fecal immunochemical testing in colorectal-cancer screening. N Engl J Med 366:697-706. doi:10.1056/NEJMoa1108895

6. Williams JG, Pullan RD, Hill J, Horgan PG, Salmo E, Buchanan GN, Rasheed S, McGee SG, Haboubi N (2013) Management of 
the malignant colorectal polyp: ACPGBI position statement. Colorectal Dis 15:1-38. doi:10.1111/codi.12262

7. Chen SL, Bilchik AJ (2006) More extensive nodal dissection improves survival for stages I to III of colon cancer. Trans Meet Am Surg Assoc 124:267-275. doi:10.1097/01.sla.0000237655. 11717.50

8. Kelder W, Inberg B, Schaapveld M, Karrenbeld A, Grond J, Wiggers T, Plukker JT (2009) Impact of the number of histologically examined lymph nodes on prognosis in colon cancer: a population-based study in the Netherlands. Dis Colon Rectum 52:260-267. doi:10.1007/DCR.0b013e3181979164

9. Dawson K, Wiebusch A, Thirlby RC (2010) Preoperative tattooing and improved lymph node retrieval rates from colectomy specimens in patients with colorectal cancers. Arch Surg 145:826-830. doi:10.1001/archsurg.2010.180

10. Horne J, Bateman AC, Carr NJ, Ryder I (2014) Lymph node revealing solutions in colorectal cancer: should they be used routinely? J Clin Pathol 67:383-388. doi:10.1136/jclinpath-2013202146

11. Rosenberg R, Friederichs J, Schuster T, Gertler R, Maak M, Becker K, Grebner A, Ulm K, Höfler H, Nekarda H, Siewert J-R (2008) Prognosis of patients with colorectal cancer is associated with lymph node ratio: a single-center analysis of 3,026 patients over a 25-year time period. Ann Surg 248:968-978. doi:10.1097/ SLA.0b013e318190eddc

12. Rahbari NN, Bork U, Motschall E, Thorlund K, Büchler MW, Koch M, Weitz J (2012) Molecular detection of tumor cells in regional lymph nodes is associated with disease recurrence and poor survival in node-negative colorectal cancer: a systematic review and meta-analysis. J Clin Oncol 30:60-70. doi:10.1200/ JCO.2011.36.9504

13. Hyslop T, Waldman SA (2013) Molecular staging of node negative patients with colorectal cancer. J Cancer 4:193-199. doi:10. 7150/jca.5830

14. Sloothaak DAM, Sahami S, van der Zaag-Loonen HJ, van der Zaag ES, Tanis PJ, Bemelman WA, Buskens CJ (2014) The prognostic value of micrometastases and isolated tumour cells in histologically negative lymph nodes of patients with colorectal cancer: a systematic review and meta-analysis. Eur J Surg Oncol 40:263-269. doi:10.1016/j.ejso.2013.12.002

15. Sirop S, Kanaan M, Korant A, Wiese D, Eilender D, Nagpal S, Arora M, Singh T, Saha S (2011) Detection and prognostic impact of micrometastasis in colorectal cancer. J Surg Oncol 103:534-537. doi:10.1002/jso.21793

16. Wanebo HJ, LeGolvan M, Paty PB, Saha S, Zuber M, D'Angelica MI, Kemeny NE (2012) Meeting the biologic challenge of colorectal metastases. Clin Exp Metastasis 29:821-839. doi:10.1007/ s10585-012-9517-x

17. Croner RS, Geppert C-I, Bader FG, Nitsche U, Späth C, Rosenberg R, Zettl A, Matias-Guiu X, Tarragona J, Güller U, Stürzl M, Zuber M (2014) Molecular staging of lymph node-negative colon carcinomas by one-step nucleic acid amplification (OSNA) results in upstaging of a quarter of patients in a prospective, European, multicentre study. Br J Cancer 110:2544-2550. doi:10. 1038/bjc. 2014.170

18. Güller U, Zettl A, Worni M, Langer I, Cabalzar-Wondberg D, Viehl CT, Demartines N, Zuber M (2012) Molecular investigation of lymph nodes in colon cancer patients using one-step nucleic acid amplification (OSNA): a new road to better staging? Cancer 118:6039-6045. doi:10.1002/cncr.27667

19. Iddings D, Ahmad A, Elashoff D, Bilchik A (2006) The prognostic effect of micrometastases in previously staged lymph node negative (N0) colorectal carcinoma: a meta-analysis. Ann Surg Oncol 13:1386-1392. doi:10.1245/s10434-006-9120-y

20. Bartels SAL, van der Zaag ES, Dekker E, Buskens CJ, Bemelman WA (2012) The effect of colonoscopic tattooing on lymph node retrieval and sentinel lymph node mapping. Gastrointest Endosc 76:793-800. doi:10.1016/j.gie.2012.05.005

21. Kang J, Park HS, Kim I, Song Y, Baik SH, Sohn S-K, Lee KY (2015) Effect of preoperative colonoscopic tattooing on lymph node harvest in $\mathrm{T} 1$ colorectal cancer. Int $\mathrm{J}$ Colorectal Dis 30:1349-1355. doi:10.1007/s00384-015-2308-5

22. Feo CV, Portinari M, Zuolo M, Targa S, Matarese VG, Gafà R, Forini E, Lanza G (2015) Preoperative endoscopic tattooing to mark the tumour site does not improve lymph node retrieval in colorectal cancer: a retrospective cohort study. J Negat Results Biomed 14:9. doi:10.1186/s12952-015-0027-7

23. Spatz H, Probst A, Oruzio D, Anthuber M, Messmann H, Arnholdt HM, Märkl B (2010) Sentinel lymph node mapping as a side-effect of colonoscopic tattooing. Surg Endosc 24:589-593. doi:10.1007/s00464-009-0641-x

24. Viehl CT, Guller U, Hamel CT, Riehle HM, Plaass C, Marti WR, Oertli D, Zuber M (2006) Carbon dye staining of sentinel lymph nodes facilitates microstaging of colon cancer patients. World $\mathrm{J}$ Surg 30:453-456. doi:10.1007/s00268-005-0336-y

25. Cahill RA, Lindsey I, Cunningham C (2010) Sentinel node mapping by colonic tattooing. Surg Endosc Other Interv Tech 24:2365-2366. doi:10.1007/s00464-010-0941-1

26. Peg V, Espinosa-Bravo M, Vieites B, Vilardell F, Antúnez JR, de Salas MS, Delgado-Sánchez JJ, Pinto W, Gozalbo F, Petit A, Sansano I, Del Mar Téllez M, Rubio IT (2013) Intraoperative molecular analysis of total tumor load in sentinel lymph node: a new predictor of axillary status in early breast cancer patients. Breast Cancer Res Treat 139:87-93. doi:10.1007/s10549-0132524-z

27. Yamamoto H, Tomita N, Inomata M, Furuhata T, Miyake $Y$, Noura S, Kato T, Murata K, Hayashi S, Igarashi S, Itabashi M, Kameoka S, Matsuura N (2015) OSNA-assisted molecular staging in colorectal cancer: a prospective multicenter trial in Japan. Ann Surg Oncol. doi:10.1245/s10434-015-4880-x

28. Yamamoto H, Sekimoto M, Oya M, Yamamoto N, Konishi F, Sasaki J, Yamada S, Taniyama K, Tominaga H, Tsujimoto M, Akamatsu H, Yanagisawa A, Sakakura C, Kato Y, Matsuura N (2011) OSNA-based novel molecular testing for lymph node metastases in colorectal cancer patients: results from a multicenter clinical performance study in Japan. Ann Surg Oncol 18:1891-1898. doi:10.1245/s10434-010-1539-5

29. Oezkan F, Khan AM, Hager T, Freitag L, Christoph D, Darwiche K (2015) OSNA: a fast molecular test based on CK19 mRNA concentration for assessment of EBUS-TBNA samples in lung cancer patients. Clin Lung Cancer. doi:10.1016/j.cllc.2015.09. 001

30. Nagai T, Niikura H, Okamoto S, Nakabayashi K, Matoda M, Utsunomiya H, Nagase S, Watanabe M, Takeshima N, Yaegashi $\mathrm{N}$ (2015) A new diagnostic method for rapid detection of lymph node metastases using a one-step nucleic acid amplification (OSNA) assay in endometrial cancer. Ann Surg Oncol 22:980-986. doi:10.1245/s10434-014-4038-2

31. Del Carmen S, Gatius S, Franch-Arcas G, Baena JA, Gonzalez O, Zafon C, Cuevas D, Valls J, Pérez A, Martinez M, Ros S, Macías CG, Iglesias C, Matías-Guiu X, de Álava E (2015) Concordance study between one-step nucleic acid amplification and morphologic techniques to detect lymph node metastasis in papillary carcinoma of the thyroid. Hum Pathol 48:132-141. doi:10.1016/j. humpath.2015.09.020

32. Rembacken B, Hassan C, Riemann JF, Chilton A, Rutter M, Dumonceau J-M, Omar M, Ponchon T (2012) Quality in screening colonoscopy: position statement of the European Society of Gastrointestinal Endoscopy (ESGE). Endoscopy 44:957-968. doi:10.1055/s-0032-1325686

33. Washington MK, Berlin J, Branton P, Burgart LJ, Carter DK, Fitzgibbons PL, Halling K, Frankel W, Jessup J, Kakar S, Minsky 
B, Nakhleh R, Compton CC (2009) Protocol for the examination of specimens from patients with primary carcinoma of the colon and rectum. Arch Pathol Lab Med 133:1539-1551. doi:10.1043/ 1543-2165-133.10.1539

34. Tsujimoto M, Nakabayashi K, Yoshidome K, Kaneko T, Iwase T, Akiyama F, Kato Y, Tsuda H, Ueda S, Sato K, Tamaki Y, Noguchi S, Kataoka TR, Nakajima H, Komoike Y, Inaji H, Tsugawa K, Suzuki K, Nakamura S, Daitoh M, Otomo Y, Matsuura N (2007) One-step nucleic acid amplification for intraoperative detection of lymph node metastasis in breast cancer patients. Clin Cancer Res 13:4807-4816. doi:10.1158/1078-0432. CCR-06-2512

35. Visser M, Jiwa M, Horstman A, Brink AATP, Pol RP, van Diest P, Snijders PJF, Meijer CJLM (2008) Intra-operative rapid diagnostic method based on CK19 mRNA expression for the detection of lymph node metastases in breast cancer. Int J Cancer 122:2562-2567. doi:10.1002/ijc.23451

36. R Core Team (2013) R: a language and environment for statistical computing. R Foundation for Statistical Computing, Vienna, Austria. http://www.R-project.org/

37. Goldstein NS (2002) Lymph node recoveries from 2427 pT3 colorectal resection specimens spanning 45 years: recommendations for a minimum number of recovered lymph nodes based on predictive probabilities. Am J Surg Pathol 26:179-189

38. Johnson PM, Malatjalian D, Porter GA (2002) Adequacy of nodal harvest in colorectal cancer: a consecutive cohort study. J Gastrointest Surg 6:883-888 (discussion 889-890)
39. Espinosa-Bravo M, Sansano I, Pérez-Hoyos S, Ramos M, Sancho M, Xercavins J, Rubio IT, Peg V (2013) Prediction of non-sentinel lymph node metastasis in early breast cancer by assessing total tumoral load in the sentinel lymph node by molecular assay. Eur J Surg Oncol 39:766-773. doi:10.1016/j.ejso.2013.03.011

40. Nicastri DG, Doucette JT, Godfrey TE, Hughes SJ (2007) Is occult lymph node disease in colorectal cancer patients clinically significant? A review of the relevant literature. J Mol Diagn 9:563-571. doi:10.2353/jmoldx.2007.070032

41. Mead R, Duku M, Bhandari P, Cree IA (2011) Circulating tumour markers can define patients with normal colons, benign polyps, and cancers. Br J Cancer 105:239-245. doi:10.1038/bjc. 2011.230

42. Bettegowda C, Sausen M, Leary RJ, Kinde I, Wang Y, Agrawal N, Bartlett BR, Wang H, Luber B, Alani RM, Antonarakis ES, Azad NS, Bardelli A, Brem H, Cameron JL, Lee CC, Fecher LA, Gallia GL, Gibbs P, Le D, Giuntoli RL, Goggins M, Hogarty MD, Holdhoff M, Hong S-M, Jiao Y, Juhl HH, Kim JJ, Siravegna G, Laheru DA, Lauricella C, Lim M, Lipson EJ, Marie SKN, Netto GJ, Oliner KS, Olivi A, Olsson L, Riggins GJ, Sartore-Bianchi A, Schmidt K, Shih le-M, Oba-Shinjo SM, Siena S, Theodorescu D, Tie J, Harkins TT, Veronese S, Wang T-L, Weingart JD, Wolfgang CL, Wood LD, Xing D, Hruban RH, Wu J, Allen PJ, Schmidt CM, Choti MA, Velculescu VE, Kinzler KW, Vogelstein B, Papadopoulos N, Diaz LA (2014) Detection of circulating tumor DNA in early- and late-stage human malignancies. Sci Transl Med 6:224ra24. doi:10.1126/scitranslmed.3007094 